\title{
Clinical and epidemiological profile of patients with nasal manifestations of granulomatous disorders in a rural tertiary care centre
}

\section{Mohit Sinha $^{1}$, Narendra Hirani ${ }^{1}$, Ajeet Kumar Khilnani ${ }^{1}$, Yash Dhamecha ${ }^{2}$, Jitendra Pareek ${ }^{3}$}

${ }^{1}$ Department of ENT, ${ }^{2}$ Department of Dermatology, ${ }^{3}$ Department of Medicine, Gujarat Adani Institute of Medical Sciences, Bhuj, Gujarat, India

Received: 21 June 2017

Revised: 04 July 2017

Accepted: 06 July 2017

\section{*Correspondence:}

Dr. Narendra Hirani,

E-mail: entdeptgaims@gmail.com

Copyright: () the author(s), publisher and licensee Medip Academy. This is an open-access article distributed under the terms of the Creative Commons Attribution Non-Commercial License, which permits unrestricted non-commercial use, distribution, and reproduction in any medium, provided the original work is properly cited.

\section{ABSTRACT}

Background: Most of the times granulomatous disorders have obvious manifestations; however, sometimes they are difficult to diagnose. A literature review reveals that patients with granulomatous diseases may be frequently incorrectly diagnosed and treated. At present limited data is available on the clinical and epidemiological profile of such patients in rural India. As such rural setup lacks the expert services of rheumatologist and the patients are frequently inconsistent with diagnostic protocols despite best efforts of the clinicians.

Methods: This is a prospective study conducted in a tertiary care centre at Bhuj, Gujarat, India between January 2016 and May 2017. Patients included in the study had multi systemic complaints along with nasal manifestations such as recurrent epistaxis, saddling, synechia or swelling over nose. These patients were subjected to detailed history taking including demographic profile. They underwent detailed ENT examination, biopsies, radiological and serological tests and were discussed at multidisciplinary review meetings which involved physicians, otorhinolaryngologists, dermatologist, ophthalmologist, pathologist and radiologist.

Results: Of the 19 patients included in this study, 53\% patients were females. 84\% (16 patients) belonged to rural household and 68\% (13 patients) belonged to lower socioeconomic status. 9 patients (47\%) were diagnosed with tuberculosis while Wegener's granulomatosis and leprosy accounted for 3 cases (16\%) each. 2 patients each were diagnosed with Cutaneous Leishmaniasis and fungal granulomas respectively. The average period between onset of symptoms and final diagnosis was 8 months. However, it took an average of 4.75 days after patient arrived at our centre to reach a final diagnosis.

Conclusions: Early diagnosis of granulomatous disorders requires a multidisciplinary approach. The role of ENT surgeons is obvious as many granulomatous disorders have nasal manifestations. A multidisciplinary approach helps cut short the time between onset of disease and diagnosis, thus benefitting the patients by reducing the hospital stay and visits as most of these illnesses require outpatient treatment.

Keywords: Fungal granuloma, Granulomatous disorders, Leishmaniasis, Tuberculosis, Wegener's granulomatosis

\section{INTRODUCTION}

Most of the times granulomatous disorders have obvious manifestations; however, sometimes they are difficult to diagnose. A literature review reveals that patients with granulomatous diseases may be frequently incorrectly diagnosed and treated. ${ }^{1}$ At present limited data is available on the clinical and epidemiological profile of 
such patients in rural India. As such rural setup lacks the expert services of rheumatologist and the patients are frequently inconsistent with diagnostic protocols despite best efforts of the clinicians. The present study highlights the clinical and epidemiological profile of patients having granulomatous disorders along with nasal manifestation and the attendant issues.

\section{Objectives}

This study was carried out to bring out the clinicoepidemiological profile of granulomatous disorders with nasal manifestations and also to highlight the role of multidisciplinary team approach in diagnosing cases of multisystemic granulomatous disorders.

\section{METHODS}

We included all cases referred to us or who came to our outpatient department between January 2016 and May 2017 with multi systemic complaints and nasal manifestations. At the first OPD visit patients were subjected to detailed history taking, nose and throat endoscopies and biopsies. Nasal swabs were sent for acid fast bacilli and $\mathrm{KOH}$ staining and culture. Biopsies were taken from the lesions of nose. In case of a septal perforation biopsy was taken after removing the crust from the margins of the perforation. In case of masses or suspected fungal lesions additional biopsies were taken from body of middle turbinate bilaterally. Patients were aggressively investigated including complete blood counts, ESR, serum liver function test, serum renal function tests, serum ANCA and ANA titres, VDRL, ACE inhibitor test, RBS and routine urine microscopy.

Radiological investigations included chest X-Ray, CT scan nose and para nasal sinuses and MRI orbit (if patient complained of proptosis or diminution of vision). The case was discussed in view of the history, clinical picture, serological and radiological tests in a multi-disciplinary conference consisting of physicians, otorhinolaryngologists, dermatologist, ophthalmologist, pathologist and radiologist.

Recommendations of the committee were combined with evidence based treatment after confirmation of a granulomatous disorder and then the patients were followed up for minimum of 6 months to note resolution of presenting symptoms.

The clinico-epidemiological data was analysed using descriptive statistics of mean and percentage.

\section{RESULTS}

Of the 19 patients included in this study, 53\% patients were females. $84 \%$ (16 patients) belonged to rural household and 68\% (13 patients) belonged to lower socioeconomic status (Table 1).
Table 1: Demographic profile of patients.

\begin{tabular}{|ll|}
\hline Demographic profile & No. of patients $(\%)$ \\
\hline A. Gender & \\
\hline 1. Male & $9(47)$ \\
\hline 2. Female & $10(53)$ \\
\hline B. Socio-economic Status \\
\hline 1. Low \\
\hline 2. Middle & $14(73)$ \\
\hline 3. Upper & $4(21)$ \\
\hline C. Residence & $1(6)$ \\
\hline 1. $\quad$ Rural & \\
\hline 2. Urban & $16(84)$ \\
\hline
\end{tabular}

From Figure 1 it is evident that maximum patients in our study $(42 \%)$ had tuberculosis, followed by Wegener's granulomatosis (16\%), leprosy $(16 \%)$, leishmaniasis (11\%), fungal granuloma (10\%) and lupus $(5 \%)$.

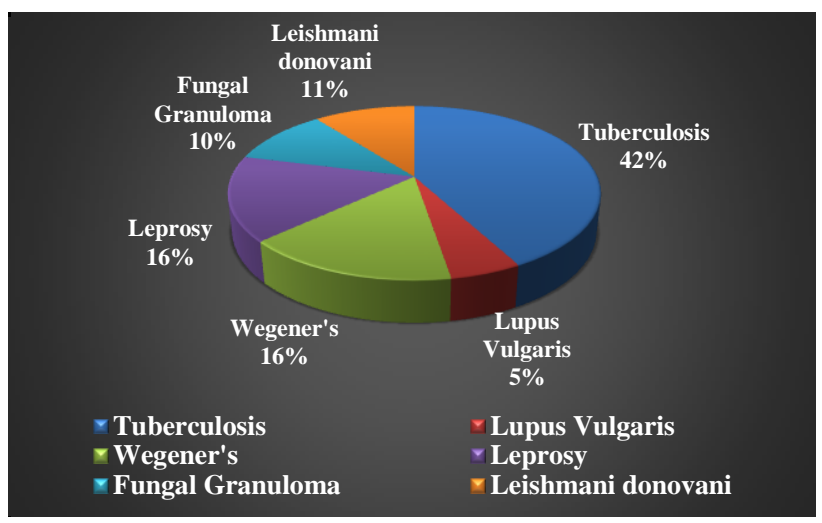

Figure 1: Patient's distribution according to the diagnosed disorder.

Symptom analysis revealed that epistaxis was the most common complaint, present in 7 patients (37\%) (Table 2). Epistaxis was seen in 5 patients of Tuberculosis and 2 patients of Wegener's. The other common symptom was recurrent fever which was present in 6 patients $(32 \%)$. It was interesting to note that one case of a 55 year old female with Wegener's, with history of fever and cough, was earlier misdiagnosed as tuberculosis by a private physician. In the above patient, headache and eye congestion prompted us to consider it as probably orbital complications of underlying sinus disease (Figure 2). Nodules and cutaneous lesions are rather characteristic features of underlying disease; however, a case of lupus vulgaris presented troublesome diagnosis because of lack of fever or typical appearance of lupus like lesion and absence of pain, nodules or previous history of Tuberculosis (Figure 3). Eye symptoms of proptosis and diminution of vision were present in both cases of fungal granulomas.

The patient workup analysis revealed that maximum patients could be diagnosed with the help of routine investigations such as complete blood count, liver 
function tests, renal function test and Chest-X Ray. ENT examination included neck node examination, rigid nasal endoscopic (RNE) examination and biopsy from any lesion in nose. Special tests like ANCA, ANA, ACE and
VDRL were ordered if no diagnoses could be reached from the above tests after discussion at the multidisciplinary meet.

Table 2: Symptom profile of patients.

\begin{tabular}{|llllllll|}
\hline Symptom & Tuberculosis & Wegener's & Leprosy & $\begin{array}{l}\text { Fungal } \\
\text { granuloma }\end{array}$ & Leishmaniasis & $\begin{array}{l}\text { Total } \\
\text { patients }\end{array}$ & $\begin{array}{l}\text { \% of } \\
\text { patients }\end{array}$ \\
\hline Epistaxis & 5 & 2 & 0 & 0 & 0 & 7 & 36.84 \\
\hline Saddling of nose & 1 & 0 & 0 & 0 & 0 & 3 & 15.79 \\
\hline Fever & 4 & 1 & 0 & 1 & 0 & 0 & 31.58 \\
\hline Nasal block & 0 & 0 & 1 & 1 & 2 & 3 & 15.79 \\
\hline $\begin{array}{l}\text { Non healing } \\
\text { ulcer/Nodule }\end{array}$ & 1 & 0 & 0 & 0 & 0 & 4 & 21.05 \\
\hline Recurrent cold & 2 & 1 & 0 & 1 & 0 & 3 & 15.79 \\
\hline Eye congestion & 0 & 1 & 0 & 2 & 0 & 3 & 15.79 \\
\hline $\begin{array}{l}\text { Diminution of } \\
\text { Vision }\end{array}$ & 0 & 1 & 0 & 2 & & & 3 \\
\hline
\end{tabular}

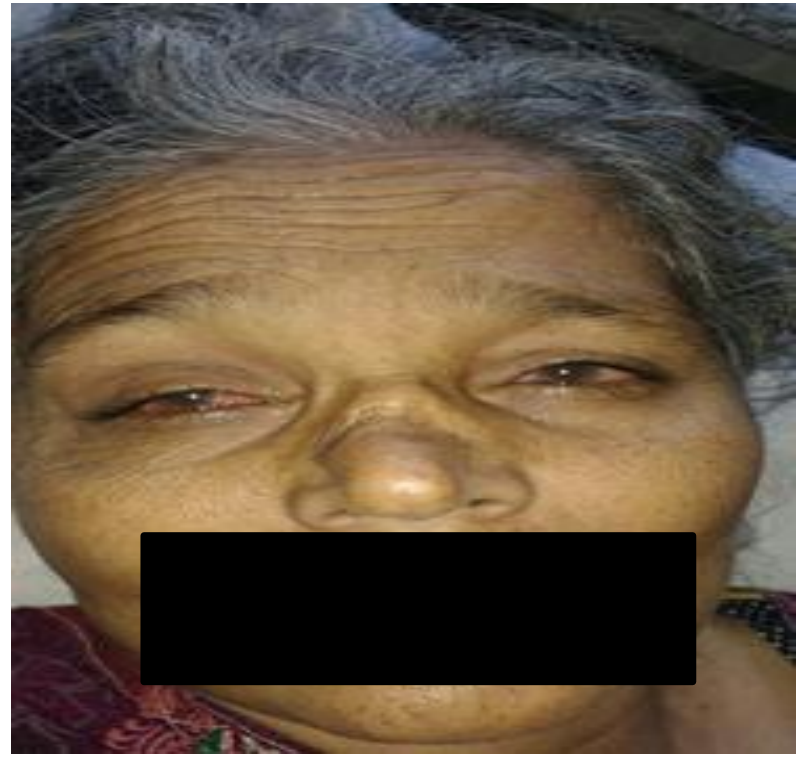

Figure 2: Clinical picture in Wegener's (note saddling of nose and redness of eyes).

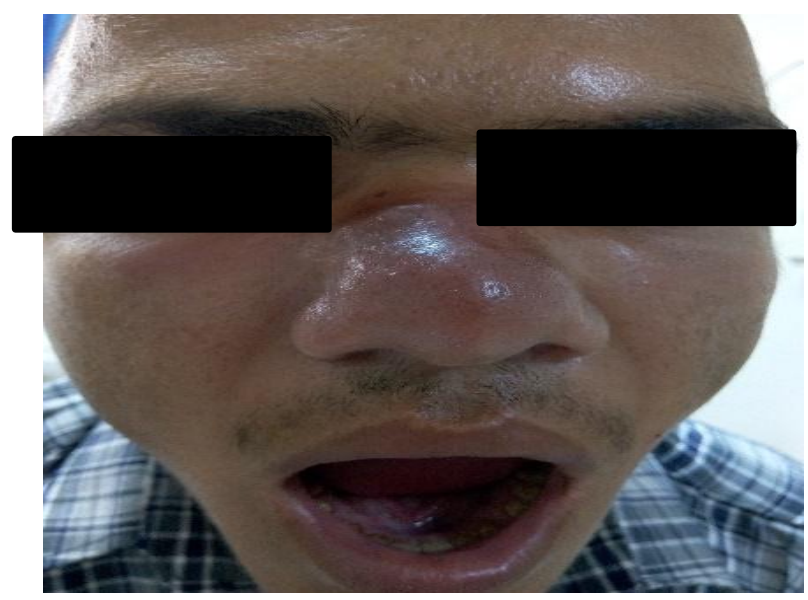

Figure 3: Clinical picture in lupus vulgaris (note the atypical appearance).
The patients' significant findings on RNE included septal ulceration, septal perforation and areas of granulations on middle turbinate or on mucocutaneous junction (Figure4). In one case of chronic granulomatous fungal disease, the gross appearance of polyposis was deceptive, but the brittle sensation and slightly vascular region followed by biopsy helped in clinching the evasive diagnosis.

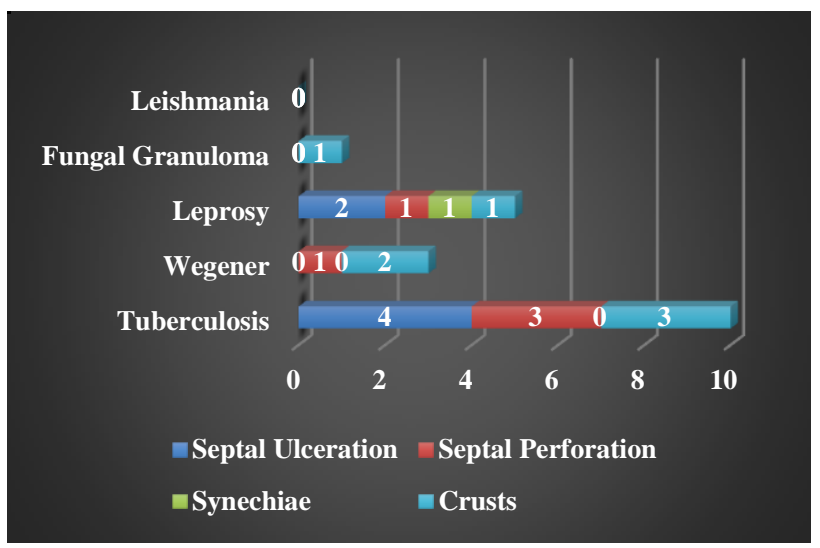

Figure 4: Nasal endoscopic findings.

It must be mentioned that the average time taken by the patients to reach us varied from 3 months to 2 and half years and all patients, except for 6 cases of tuberculosis and 1 patient of leprosy, did not have a confirmed diagnosis at the time of presentation. After coming to us a diagnosis was reached in an average 4.2 days over an average of 2 meetings of multidisciplinary committee. Also 2 cases were presented in multidisciplinary integrated teaching symposiums for post graduate teaching.

\section{DISCUSSION}

The study location was a tertiary care hospital in rural arid region. The patients majorly belonged to poor socio economic strata and were too poor to even follow up on a 
regular basis for proper diagnosis and management. On average patients came within a radius of $150 \mathrm{sq} \mathrm{km}$.

In a literature review we could not find overall incidence of granulomatous disorders with nasal manifestations. However, a review by Zafar et al and Tondon et al on histopathological characteristics of lesions of nose and nasopharynx, as shown in Table 3, lists the incidence of these diseases. ${ }^{2,3}$

Table 3: Incidence of granulomatous disorders of nose and nasopharynx.

\begin{tabular}{|l|ll|}
\hline Granulomatous lesions & \multicolumn{2}{|l|}{ Incidence in } \\
& Zafar et $\mathrm{al}^{2}$ & Tondon et $\mathrm{al}^{3}$ \\
\hline Rhinoscleroma & 4.83 & 9 \\
\hline Sino nasal tuberculosis & $<1$ & $<1$ \\
\hline $\begin{array}{l}\text { Wegener's } \\
\text { granulomatosis }\end{array}$ & - & - \\
\hline
\end{tabular}

Tuberculosis with sinonasal manifestations is relatively rare. ${ }^{2,3}$ Extra pulmonary TB of head and neck area is very rare and constitutes only $0.1-1 \%$ of all cases. ${ }^{4}$ In our series, 8 cases had primary pulmonary tuberculosis with nasal manifestations. Cutaneous tuberculosis (CTB) comprises a small fraction $(2 \%)$ of cases of $\mathrm{TB}$, and the incidence has decreased from $2 \%$ to $0.5 \% .^{5,6}$ The site and picture of this disease may be confusing, leading to delayed diagnosis as in our case. Based on bacterial load, cutaneous tuberculosis is classified into paucibacillary forms (e.g., lupus vulgaris, tuberculosis verrucosa cutis, and tuberculids) and multibacillary forms (e.g., scrofuloderma, tuberculous chancre, and acute military tuberculosis). ${ }^{7}$ Lupus is the commonest form of cutaneous $\mathrm{TB}$, characterized by reddish plaques and apple jelly nodule on diascopy. ${ }^{8}$ In our case, the lesion over the nose did not show the typical appearance but we could reach a specific diagnosis with biopsy despite no history of fever, cough and a normal chest X-ray.

Wegener's granulomatosis is a systemic disease with a classic triad of necrotizing vasculitis, nephritis and inflammation of upper and lower respiratory tract. ${ }^{9,10}$ However, in $28 \%$ cases they have primarily ENT manifestations without renal or vasculitic presentation. ${ }^{9}$ In our series, one patient was earlier misdiagnosed as tuberculosis by a private physician. Headache and eye congestion in this patient prompted us to consider it as probably orbital complications of underlying sinus disease. This patient in particular justifies the tag of Wegener's being great masquerader. ${ }^{11}$

Cutaneous leishmaniasis is seen in arid regions of India like Rajasthan and Kutch. ${ }^{12,13}$ But, due to vector control program, there has been a reduction in case load. Most of the time lesions of cutaneous leishmaniasis are over face, ranging from nodular to nodulo-erythematous lesions. ${ }^{14,15}$ The diagnosis of cutaneous leishmaniasis relies on the identification of LD bodies in either a direct smear of the lesion or in a tissue section.

\section{CONCLUSION}

Early diagnosis of granulomatous disorders requires a multidisciplinary approach. The role of ENT surgeons is obvious as many granulomatous disorders have nasal manifestations. A multidisciplinary approach helps cut short the time between onset of disease and diagnosis, thus benefitting the patients by reducing the hospital stay and visits as most of these illnesses require outpatient treatment.

Funding: No funding sources

Conflict of interest: None declared

Ethical approval: The study was approved by the Institutional Ethics Committee

\section{REFERENCES}

1. Heyworth P, Cross A, Curnutte J. Chronic granulomatous disease. Curr Opin Immunol. 2003;15(5):578-84.

2. Zafar U, Khan N, Afroz N, Hasan S. A Clinicopathological study of non-neoplastic lesions of nasal cavity and paranasal sinuses. Indian $\mathbf{J}$ Pathol Microbiol. 2008;51:26-9.

3. Tondon PL, Gulati J, Mehta N. Histological study of polypoidal lesions in the nasal cavity. Indian $\mathbf{J}$ Otolaryngol. 1971;23:3-10.

4. Weir MR, Thornton GF. Extrapulmonary tuberculosis. Experience of a community hospital and review of the literature. Am $\mathrm{J}$ Med. 1985;79:467-78.

5. Kumar B, Kaur S. Pattern of cutaneous tuberculosis in North India. Indian J Dermatol Venereol Leprol. 1986;52(4):203-7.

6. Sehgal VN, Srivastava G, Khurana VK, Sharma VK, Bhalla P, Beohar PC. An appraisal of epidemiologic, clinical, bacteriologic, histopathologic, and immunologic parameters in cutaneous tuberculosis. Int $\mathbf{J}$ Dermatol. 1987;26(8):521-6.

7. Tigoulet F, Fournier V, Caumes E. Clinical forms of the cutaneous tuberculosis. Bull Soc Pathol Exot. 2003;96(5):362-7.

8. Kumar B, Muralidhar S. Cutaneous tuberculosis: a twenty-year prospective study. Int $\mathbf{J}$ Tuberc Lung Dis. 1999;3(6):494-500.

9. Morales-Angulo C, García-Zornoza R, ObesoAgüera S, Calvo-Alén J, González-Gay MA. Ear, Nose and Throat Manifestations of Wegener's Granulomatosis (Granulomatosis With Polyangiitis). Acta Otorrinolaringol Esp. 2012;63(3):206-11.

10. Duggal L, Jain N. Limited Wegener's Granulomatosis. JIACM. 2004;5(2):186-7.

11. Sharma A, Gopalakrishan D, Nada R, Kumar S, Dogra S, Aggarwal $\mathrm{M}$, et al. Uncommon presentations of primary systemic necrotizing vasculitides: the Great Masquerades. Int J Rheum Dis. 2014;17:562-72. 
12. Wani GM, Ahmad SM, Khursheed B. Clinical study of cutaneous leishmaniasis in the Kashmir Valley. Indian Dermatol Online J. 2015;6:387-92.

13. Bhargava EK, Rana K. Cutaneous Leishmaniasis: The Grand Masquerade. Otolaryngol Head Neck Surg. 2015;153(4):681-2.

14. Kocarslan S, Turan E, Ekinci T, Yesilova Y, Apari R. Clinical and histopathological characteristics of cutaneous leishmaniasis in Sanliurfa City of Turkey including Syrian refugees. Indian J Pathol Microbiol. 2013;56:211-5.

15. Saab J, Fedda F, Khattab R, Yahya L, Loya A, Satti $\mathrm{M}$, et al. Cutaneous leishmaniasis mimicking inflammatory and neoplastic processes: a clinical, histopathological and molecular study of 57 cases. J Cutan Pathol. 2012;39(2):251-62.

Cite this article as: Sinha M, Hirani N, Khilnani AK, Dhamecha Y, Pareek J. Clinical and epidemiological profile of patients with nasal manifestations of granulomatous disorders in a rural tertiary care centre. Int J Otorhinolaryngol Head Neck Surg 2017:3:807-11. 